\title{
Interaction Effect of Dual N-back Working Memory Training and Anxiety Levels on L2 Writing Performance
}

Received: 19/10/2019; Accepted: 09/12/2019

\section{Abstract}

Burgeoning interest in the role of working memory (WM) in most cognitive endeavors has led to an increase in WM training programs. Within the field second language writing, however, WM improvement interventions are scarce, and even scarcer is research into how other variables interact with WM in their effect on performance. Hence, this study examines how anxiety, often believed to be an impediment for both $\mathrm{WM}$ and writing, moderates the effect of WM training on writing. Learners' $(\mathrm{N}=80)$ writing performance was assessed before and after Dual $\mathrm{N}$-back training. Anxiety levels were examined for any interaction with the intervention. Results from ANCOVA, Pearson's correlation, and Two-Way ANOVA have revealed that writing anxiety is significantly correlated with writing performance and that the treatment group outperformed the control group even after controlling for both initial performance and anxiety levels. The findings indicate that there is a significant anxiety-treatment interaction effect on writing performance.

Keywords: Anxiety ; interaction effect ; L2 writing ; working

\section{Nawal Khelalfa *}

Sarah Merrouche

University of L'arbi Ben M'hidi (Algeria)

\section{Résumé}

L'intérêt croissant au rôle de la mémoire du travail (MT) chez les cognitivistes a mené à une progression remarquable des programmes d'entrainement de la MT. Dans le domaine de l'expression écrite la performance d'écriture en langue seconde, les recherches sur le rôle de la MT, et l'intérêt à la façon dont les autres variables intéragissent avec la MT, se font rares. Donc, ce travail de recherche examine comment l'anxiété, souvent considérée comme un obstacle à la fois à la MT et à l'activité rédactionnelle, régule l'effect des programmes d'entrainement de la MT sur l'activité rédactionnelle. Nous avons évalué les productions écrites de 80 apprenants avant et après l'entrainement Dual N-Back. Les niveaux d'anxiété ont été mesurés pour observer toute éventuelle interaction avec l'intervention. Les résultats d'ANCOVA, du coéficient de corrélation de Pearson, et l'ANOVA à deux facteurs ont révélé qu'il existe un effet d'interaction anxiété-traitement sur les performances en écriture.

Mots clés: Anxiété ; effet d'interaction ; écriture ; Mémoire de travail

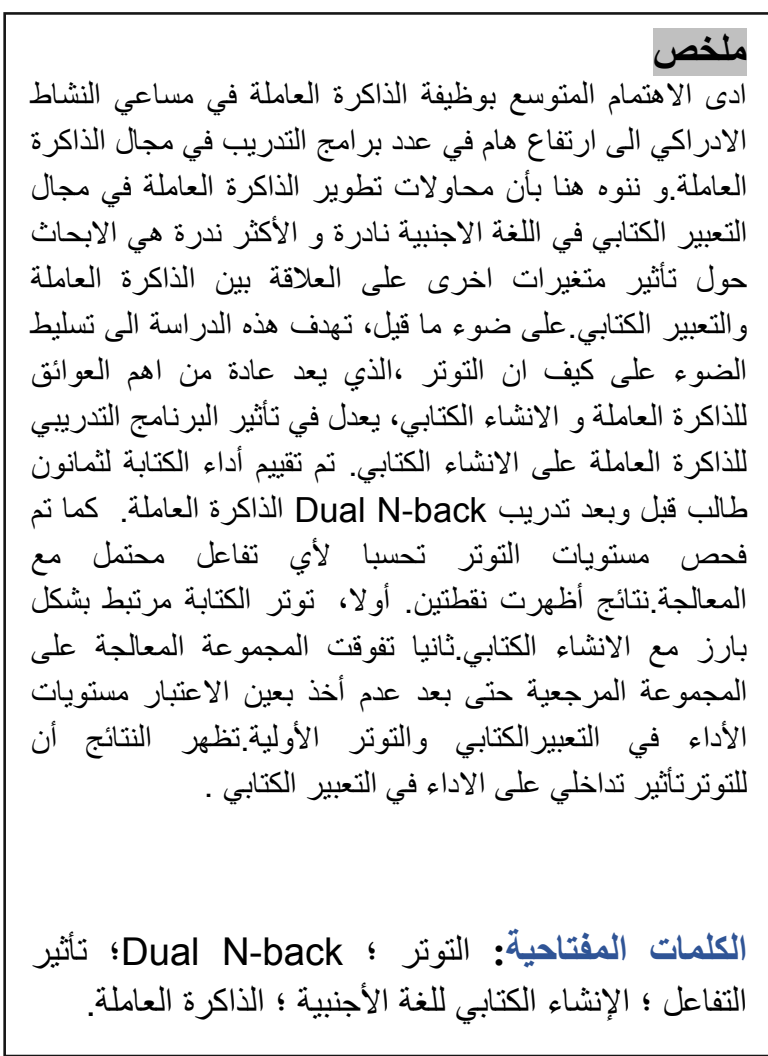

\footnotetext{
* Corresponding author, e-mail: Nawalkhelalfa@yahoo.com
} 


\section{I- Introduction :}

To skillfully produce an effective composition, a writer is expected to meet a range of linguistic and extra-linguistic criteria, from mechanics and word choice to structure, coherence, cohesion, and pragmatic aspects of text construction. Hence, the writer is faced with the task of constantly juggling various demands while trying to translate her thoughts on paper ${ }^{1}$, which often leads to a cognitive overload ${ }^{2}$. This is mainly because information needed to process such demands is stored in (WM), which has limited capacity ${ }^{1}$. Accordingly, it seems that writers, especially English as a Foreign Language (EFL) writers, may fall back when it comes to producing an effective text which succeeds in meeting all the demands of writing. It seems that even when L2 writers have the necessary knowledge to successfully meet each demand in isolation, when it comes to managing all of them simultaneously, especially in a timedwriting task, these learners often produce insufficient texts. A perfectly grammatical essay, for instance, may be insufficient in structure or coherence. Likewise, a coherent essay may lack in content or punctuation, or vice versa ${ }^{3}$.

Since smaller WMC is believed to be responsible for more strain being placed on an individual, it should be the case that an increase in WMC would reduce cognitive load, and an increase in WMC is believed to take place after WM training (WMT). Hence, this study attempts to examine whether WMT, implemented in an attempt to increase WMC, is effective in improving writing performance. However, WM functioning has been found to be affected by various other factors, one of which is anxiety. Likewise, L2 writing is widely believed to be affected by anxiety. This study, therefore, examines the interaction effects of WMT and anxiety on L2 writing performance.

\section{I.1. Working Memory:}

A central constituent of nearly any human function, WM is defined as the collection of cognitive resources used to process information simultaneously with other mental tasks ${ }^{4}$. The most prominent of WM models was initially devised by Baddeley and Hitch ${ }^{5}$. The model was comprised three components: the central executive (CE) (responsible for controlling attention), the phonological loop (responsible for processing language), and the visuospatial sketchpad (responsible for processing visual and spatial stimuli). Baddeley's ${ }^{6}$ revised model added a fourth component, the episodic buffer (an interface between the other components) ${ }^{7}$. The model has been adopted as a theoretical framework for research in a wide range of fields, including language acquisition and learning. Numerous studies have revealed that WM is a significant contributor to first language (L1) acquisition ${ }^{8}$ as well as L2 learning ${ }^{9,10}$.

\section{2. Dual N-back:}

With proliferating research on WM over the last decade also came proliferating attempts at enhancing WMC and consequently improving performance on various cognitive tasks. The most commonly-employed WMT program today is the dual Nback task, adapted in 2003 by Susanne Jaeggi and her colleagues from Kirchner's ${ }^{11}$ single $\mathrm{N}$-back task ${ }^{12}$. In the task, two stimuli, one visual and one auditory, are presented simultaneously in series, both to be remembered together. These two N-back tasks, when performed simultaneously, were originally claimed to improve WMC, which in turn is believed to be transferred to other, untrained, cognitive tasks such as fluid intelligence after eight weeks of training ${ }^{13}$. Such claims raised a wave of controversy on the effectiveness of dual N-back training which has yet to be settled today. While some studies on WMT have reported only near transfer effects, others have reported far transfer effects, and others have reported no effects ${ }^{14}$. To the knowledge of the researchers, no studies are available in the literature which examine the far-transfer effects of the training program on L2 writing performance. 


\section{3. WM and writing:}

Various empirical as well as theoretical studies have also been carried out in attempt to establish a relationship between the two constructs ${ }^{2,15,16,17}$. Kellogg ${ }^{18}$ asserted that every writing process is dependent on WM except the executing subprocess, mainly due to its purely physical (and mostly automatic) rather than cognitive nature. In studying the significance of WMC in writing, researchers have focused on potential cognitive overload. The demands placed on the writer to translate her thoughts into written form consumes a significant amount of WM resources, so much that the resources available for planning and other processes are limited; hence, performance is likely hindered ${ }^{19}$. This is because the writer is faced with numerous other demands: 1) making sure her spelling, handwriting, and grammar are up to standards, 2) trying to predict and meet the expectations of the readers as well constantly making sure she is not deviating from the task or the prompt, 3) juggling any newly-generated or unexpected ideas, in which case she has to make the decision of either delaying this newly-generated information until she has finished her current task or finishing her current task at the expense of maybe losing fresh ideas. Other demands, which may be seen as constraints, are external factors such as time management or environmental distractors. All of these simultaneously being juggled are the responsibility of the WM system, a system which is already limited in both storage and processing capacity ${ }^{1}$.

Accordingly, all of this seems to be even truer for those writing in a non-native language. These learners are not only faced with all of the cognitive load and strain already associated with writing, but they are also faced with the added strain of managing it in a language foreign to them. They may put forth more effort than natives when retrieving lexical items or generating grammatically or stylistically effective sentences or paragraphs. Sometimes they may be faced with cultural barriers, which may prevent them from effectively writing to a certain audience. $\mathrm{Lu}^{20}$ stated that "language learners, when they are writing in their L2, they must use part of their cognitive resources to focus on the language so that other functions, such as higherorder functions for organization and discourse cannot be engaged at full capacity" (p.176).

\section{4. The role of anxiety:}

According to Eysenck and Calvo's ${ }^{21}$ Processing Efficiency Theory, worry and anxiety lead to a decrease in WM storage and processing capacity. This is because worry leads to a pre-occupation with failure or being judged, and this preoccupation consumes a significant amount of already-limited resources of WM, leaving less resources and hindering processing and storage capacity for devoted to the task at hand. The debilitative role of anxiety in WM is supported by numerous researchers ${ }^{21,22}$. Moran $^{23}$ conducted a meta-analysis of 177 samples which includes 22,061 participants and found a significant negative correlation between anxiety and WMC. When a particular task relies on WM, under certain levels of anxiety, WMC or processing is hindered by anxiety and hence the task is as well. The role of anxiety has also been found to play a debilitative role in L2 writing ${ }^{24,25,26}$.

Based on the evidence available in the literature, this study set out to test whether anxiety functions as a significant moderator in the relationship between WMT and L2 writing performance. It set out to test whether WMT affects L2 writing performance and whether anxiety levels alter, or interact with, the effect of the intervention on L2 writing performance. Accordingly, the aim of this study is two-fold. First, it aims to assess the extent of the far-transfer effects, if any, of Dual-N back WMT program on L2 writing performance. Second, it aims to examine any potential anxiety-treatment interaction effects on writing performance. 
The following research questions were adopted:

1. Is there a main treatment effect of dual N-back WMT on EFL learners' writing performance?

2. Are EFL learners' anxiety levels correlated with their writing performance?

3. Is there a significant anxiety-treatment interaction effect on L2 writing performance?

\section{II- Methods and Materials:}

\section{1. Participants:}

The sample consists of 80 Algerian university students enrolled as second year students of English as a Foreign Language (EFL) at L'arbi Ben M'hidi University in Oum El Boughi, Algeria. The researcher assigned 42 participants to the control group and 38 to the experimental group. Of the total sample, 15 are male and 65 are female. This predominance of females over males reflects the same predominance across the whole faculty and department.

\section{2. Materials:}

The researcher adapted Cheng's ${ }^{27}$ self-report scale, the Second Language Writing Anxiety Inventory (SLWAI), for measuring writing anxiety. The questionnaire contains 22 items answered on a 5-point Likert scale, with 0 denoting 'strongly disagree' and 4 denoting 'strongly agree'. The inventory's original internal consistency yielded a Cronbach's alpha of $.91^{27}$. Results from this study yielded an alpha of .92 , indicating strong internal consistency. Writing performance was operationalized using a writing prompt to which students were expected to respond in the form of an essay. They were then evaluated based on a 30-poimt evaluation rubric which was divided into five categories of writing: organization, development, word choice, sentence structure, and mechanics. Two raters, both doctoral candidates in English, evaluated the essays and discussed cases of disagreement until agreement was reached. The researcher ran an inter-rater reliability analysis using the inter-class correlation coefficient, which yielded a coefficient of .94 , indicating strong inter-rater reliability.

\section{3. The intervention}

The intervention for this study is WMT, applied via the Dual N-back program (Jaeggi et al., 2003). The task is typically completed using some form computer program; in this intervention, the subjects completed the task mostly on their mobile devices, some on their phones and others on their tablets or iPads. In the game, the participants were presented with a large square which is divided into nine smaller inner squares (three rows and three columns of inner squares. All of the squares are active with the exception of the middle square. At each position one of the squares flashes (a visual stimuli) and, at the same time, a letter is uttered. Each participant was responsible for remembering both stimuli $n$ positions back so that they indicate when the current position matches. The current position may match in terms of only one stimulus (either visual or auditory), or it can match in terms of both stimuli. Subjects were responsible for stating either case. As each subject matches each level, they progress to the next level, in which the $n$ increases; for instance, from two positions back to three then four positions back, and the game becomes more difficult. At the end of every session, they are provided with the statistics for their performance

Participants were provided with a grid to fill out at each trial, reporting scores for position, for sound, and the total score. Since significant effects of dual N-back WMT have been reported after 3 weeks of training (a total of eight hours of training) (Jaeggi et al., 2008), subjects were given more than 8 hours total throughout the semester to complete the tasks in class, and those who failed to do so were asked to work at home. At the end of the intervention, the researchers collected their grids and 
screenshots of the graphical representations of what they had completed, which also included their scores and progress throughout all of the sessions. All procedures and data were applied and collected, respectively after compliance from all the subjects. They had full knowledge and provided full consent of their participation in the experiment.

\section{III- Results and discussion :}

Results from the preliminary descriptive statistics revealed that pre-test writing scores ranged from 3 to 21.5 with a mean (M) of 12.40 and a standard deviation (SD) of 4.32, from a possible score of 30. Anxiety scores ranged from 4 to 58 ( $M=26.47$, $\mathrm{SD}=12.84)$ out of 60 , and post-test writing scores ranged from 8 to $21.5(\mathrm{M}=13.56$, $\mathrm{SD}=3.34$ ). The researcher also ran tests for assumptions of parametric testing (in this case analysis of covariance, Pearson's correlation coefficient, and two-way ANOVA). The main assumptions that required statistical tests were normality and homogeneity of data. The rest of the assumptions, like the level of measurement for Pearson's correlation coefficient, ould be checked without running a statistical test. Accordingly, the boxplots indicate that data for the three variables do not contain any outliers, and results from Kolmogorov-Smirnov's test for normality indicate a normal distribution of data for pre-test writing scores $(\mathrm{D}(72)=.07, p=.533)$, post-test writing scores $(\mathrm{D}(72)$ $=.08, p=.062)$, and anxiety scores $(\mathrm{D}(72)=.089, p=.147)$. Finally, Levene's test for equality of variances indicates equal variances across groups for pre-test writing scores $(\mathrm{F}(1,78)=1.11, p=.295)$, for post-test writing scores $(\mathrm{F}(1,78)=.262, p=.297)$ and for anxiety scores $(\mathrm{F}(1,70)=.264, p=.609)$.

To answer the research questions the researcher also ran several inferential statistical tests. The first test, Analysis of Covariance (ANCOVA) was employed to test the extent to which the control and treatment groups differed in their post-test writing scores while taking into account their pre-test writing scores (in the form of a covariate). The second test, Pearson's correlation coefficient was used to examine the association between learners' anxiety scores and their writing performance. Finally, the third test, Two-Way ANOVA, was employed in order to test for treatment-anxiety interaction effects on writing scores. To avoid confounding of results, the researcher ran ANCOVA before testing for interaction to know the extent of the effect of the intervention on final writing scores after controlling for initial scores because writing scores may have been different to begin with.

Table 1- ANCOVA results controlling for pre-test scores

Dependent Variable: Post-writing

\begin{tabular}{|c|c|c|c|c|c|c|}
\hline Source & $\begin{array}{l}\text { Type III Sum of } \\
\text { Squares }\end{array}$ & $\mathrm{df}$ & Mean Square & $\mathrm{F}$ & Sig. & Partial Eta Squared \\
\hline Corrected Model & $412.972^{\mathrm{a}}$ & 2 & 206.486 & 33.791 & .000 & .467 \\
\hline Intercept & 422.065 & 1 & 422.065 & 69.070 & .000 & .473 \\
\hline Pre-writing & 396.070 & 1 & 396.070 & 64.816 & .000 & .457 \\
\hline Group & 55.094 & 1 & 55.094 & 9.016 & .004 & .105 \\
\hline Error & 470.525 & 77 & 6.111 & & & \\
\hline Total & 15585.250 & 80 & & & & \\
\hline Corrected Total & 883.497 & 79 & & & & \\
\hline
\end{tabular}

a. R Squared $=.467($ Adjusted R Squared $=.454)$ 
Results from ANCOVA (presented in Table 1) have revealed that there is a statistically significant difference between the two groups in their final writing score after controlling for their initial scores, $\mathrm{F}(1,77)=9.016, p=.004$. To gain a better understanding of how the covariate (pre-writing scores) affected the original means of the two groups, the adjusted means were referred to $(M=12.76$ for the control and $\mathrm{M}=14.44$ for the experimental group). After running ANCOVA and establishing a significant difference between groups, the researcher proceeded to assessing whether there is a significant relationship between L2 writing anxiety and L2 writing achievement. Results from the Pearson Correlation analysis indicate that a L2 writing anxiety is statistically and negatively correlated with L2 writing performance at the .01 level $(\mathrm{r}(72)=.47, p=.000)$. Hence, higher anxiety levels are associated with lower writing performance and vice versa.

Finally, after running Pearson Correlation analysis, the researcher tested for a treatment-anxiety interaction effect using two-way ANOVA. As Table 2 summarizes, the treatment itself (represented by the 'group' row) did not yield a significant effect (F $(1,72)=1.438, p=.235)$. However, having already tested the effect of the treatment when controlling for pre-test scores (via ANCOVA) and establishing an association, what remains of major importance is whether anxiety has interacted with the treatment and altered its effect on writing performance. Statistics for treatment-anxiety interaction are presented in the bold row (group * anxiety), which indicate that there was a significant treatment- anxiety interaction effect $(\mathrm{F}(3,72)=3.028, p=.036)$. Therefore, anxiety seems to interact with WM training in its effect on writing performance. Figure 1 is a graphical representation for a better understanding of the nature of the interaction effect.

Table 2- Two-way ANOVA results for interaction effect Tests of Between-Subjects Effects

\section{Dependent Variable: Post-writing}

\begin{tabular}{lc|c|c|c|c|c}
\multicolumn{1}{c}{ Source } & $\begin{array}{c}\text { Type III Sum } \\
\text { of Squares }\end{array}$ & df & $\begin{array}{c}\text { Mean } \\
\text { Square }\end{array}$ & F & Sig. & $\begin{array}{c}\text { Partial Eta } \\
\text { Squared }\end{array}$ \\
\hline Corrected Model & $237.902^{\mathrm{a}}$ & 7 & 33.986 & 3.970 & .001 & .303 \\
\hline Intercept & 9711.801 & 1 & 9711.801 & 1134.481 & .000 & .947 \\
\hline Group & 12.312 & 1 & 12.312 & 1.438 & .235 & .022 \\
\hline Anxiety & 118.402 & 3 & 39.467 & 4.610 & .006 & .178 \\
\hline Group * anxiety & $\mathbf{7 7 . 7 6 2}$ & $\mathbf{3}$ & $\mathbf{2 5 . 9 2 1}$ & $\mathbf{3 . 0 2 8}$ & $\mathbf{. 0 3 6}$ & $\mathbf{. 1 2 4}$ \\
\hline Error & 547.876 & 64 & 8.561 & & & \\
\hline Total & 14016.000 & 72 & & & & \\
\hline Corrected Total & 785.778 & 71 & & & & \\
\hline
\end{tabular}

a. R Squared $=.303$ (Adjusted R Squared $=.226$ )

As the figure shows, anxiety levels have been categorized and transformed into nominal scale for the convenience of the statistical test. Those with anxiety levels from 0-14 were categorized as 'low anxiety', those with scores of 15-29 were placed under the category of low-mid anxiety, those with scores of 30-44 were categorized as midhigh anxiety, and those with scores of 45-60 have the highest level of anxiety. 


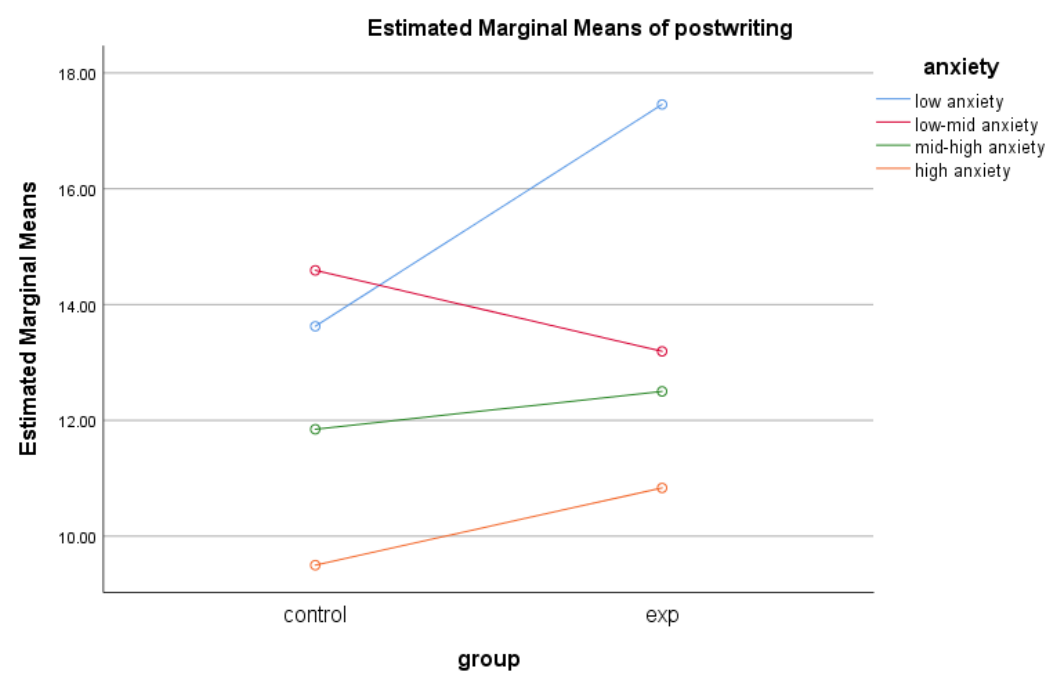

Figure 1- Graphical representation of treatment-anxiety interaction

The graphical representation allows for the comparison of the four anxiety levels simultaneously with respect to the two groups and writing achievement. It seems that the higher the anxiety levels of individuals, the lower their writing scores (estimated marginal means). This is evident when looking at the four lines; the bottom line, where the lowest performers lie, represents the highest level of anxiety while the top line, where the highest performers lie, represents the lowest level of anxiety. Moreover, when anxiety is contextualized against the two groups, it is evident that within each level of anxiety the experimental group outperformed the control group except for one level (low-mid anxiety). Hence, although the experimental group seemed to have outperformed the control group overall, there seems to be a huge variation in performance of both groups among those with different anxiety levels.

The first research question, which sought to determine whether an intervention of Dual N-back WMT affected L2 writing performance, was answered via ANCOVA, controlling for the covariate pre-test writing scores. Results revealed that, after controlling for their original writing scores, those of the experimental group performed significantly better than those of the control group, indicating that WMT does lead to far-transfer effects. These findings are in parallel with findings from Jaeggi et al. ${ }^{13}$. Also, these results suggest that WMT does have some effect on writing performance, particularly L2 writing. These findings seem to support Kellogg's ${ }^{18}$ theoretical model of how WM significantly contributes to writing. Furthermore, the findings seem to be in parallel with those of Linck et al. ${ }^{9}$, who found that WM had contributed to aspects of L2 learning and Vanderberg et al. ${ }^{17}$ and Hoskyn et al. ${ }^{16}$, who found WM to be a significant contributor to writing performance. Hence, from these findings, the researcher can cautiously conclude that the training program may have been effective in increasing WMC, which may have led to the difference in final performance between the control and the treatment group.

The second research question, which sought to determine whether L2 writing anxiety was associated with L2 writing performance, was answered via Pearson's Correlation Analysis. Results from the analysis indicate that L2 writing anxiety is significantly correlated with L2 writing performance. These findings are in parallel with those of various other researchers ${ }^{24,25,26}$, who found a debilitative effect of anxiety on L2 writing. Finally, the third question sought to determine any potential interaction effect that anxiety may have with the treatment in its effect on writing performance. Results from Two-Way ANOVA indicate that a significant interaction effect exists between L2 writing anxiety levels and the WMT in its effect on L2 writing performance. Although the researchers failed to find any studies which examine such interaction effects, these results seem to support previous research which claims that anxiety functions as a significant impediment for WM capacity ${ }^{21,22,23}$. Hence, from the current findings, not only can one conclude that anxiety is a significant factor in L2 
writing performance and WM performance, but one can also conclude that it may significantly moderate the effect of any potential interventions attempting to improve WM performance. The final results of such interventions, therefore, will likely be altered. In some cases, such interventions may appear to be ineffective. Individuals who may seem to be unaffected by WMT may actually be hindered by an external variable such as anxiety. Likewise, those performing poorly on writing tasks may also be hindered by anxiety. Hence, the role of anxiety is two-fold, it negatively affects writing performance, and it negatively affects already-limited WM capacity.

\section{IV-Conclusion:}

These findings have implications for researchers as well as practitioners. First, in gaining a better understanding of the debilitative role of anxiety in both writing and WM, researchers may be able to account for aspects of performance which may not have been accounted for previously. Particularly, these findings provide insight into the role of the complex interplay of the set variables at hand. For instance, the moderating role of anxiety in the relationship between WM and writing, particularly L2 writing, has not been researched thus far. Accordingly, these findings not only provide insight into the role of these variables, but they may also pave the way for further, more elaborate, research into the nature of each role and maybe its interaction with other factors. Second, with such findings practitioners, particularly L2 teachers and maybe course designers, can devise course content, objectives, or activities with the aim of reducing learners' anxiety levels for maximum benefit. When such precaution is taken, practitioners may be able to see improvements not only in writing performance but also in overall language learning.

\section{- Appendices :}

\section{Appendix A- Sample graphs and form for students' dual N- back scores}
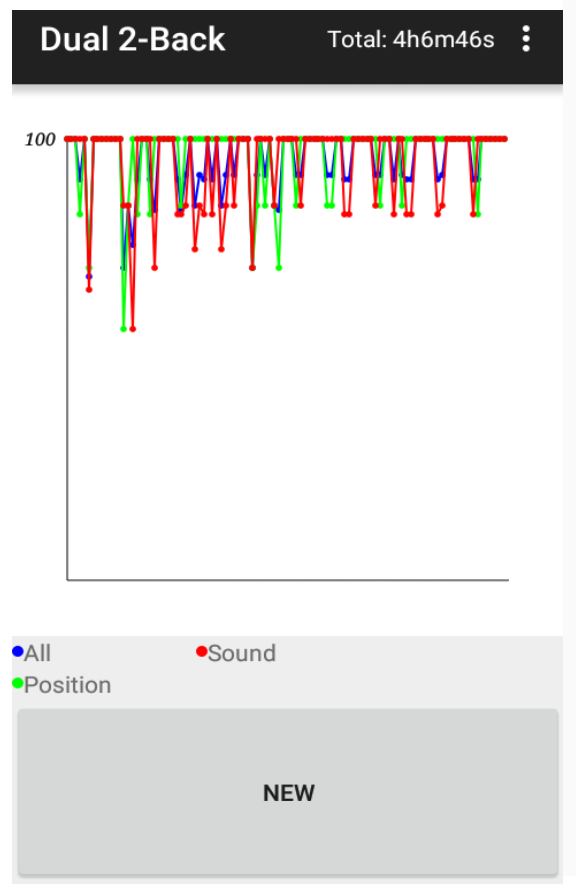
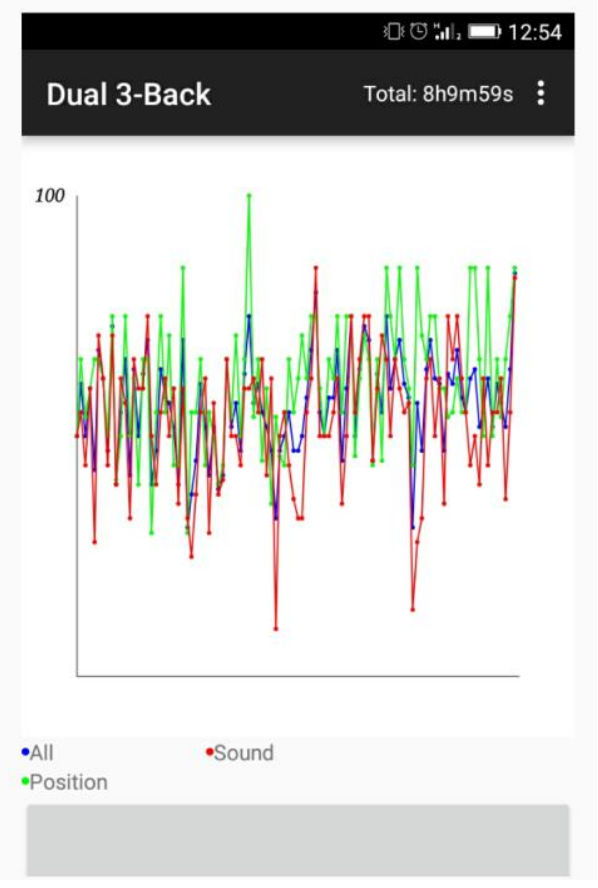


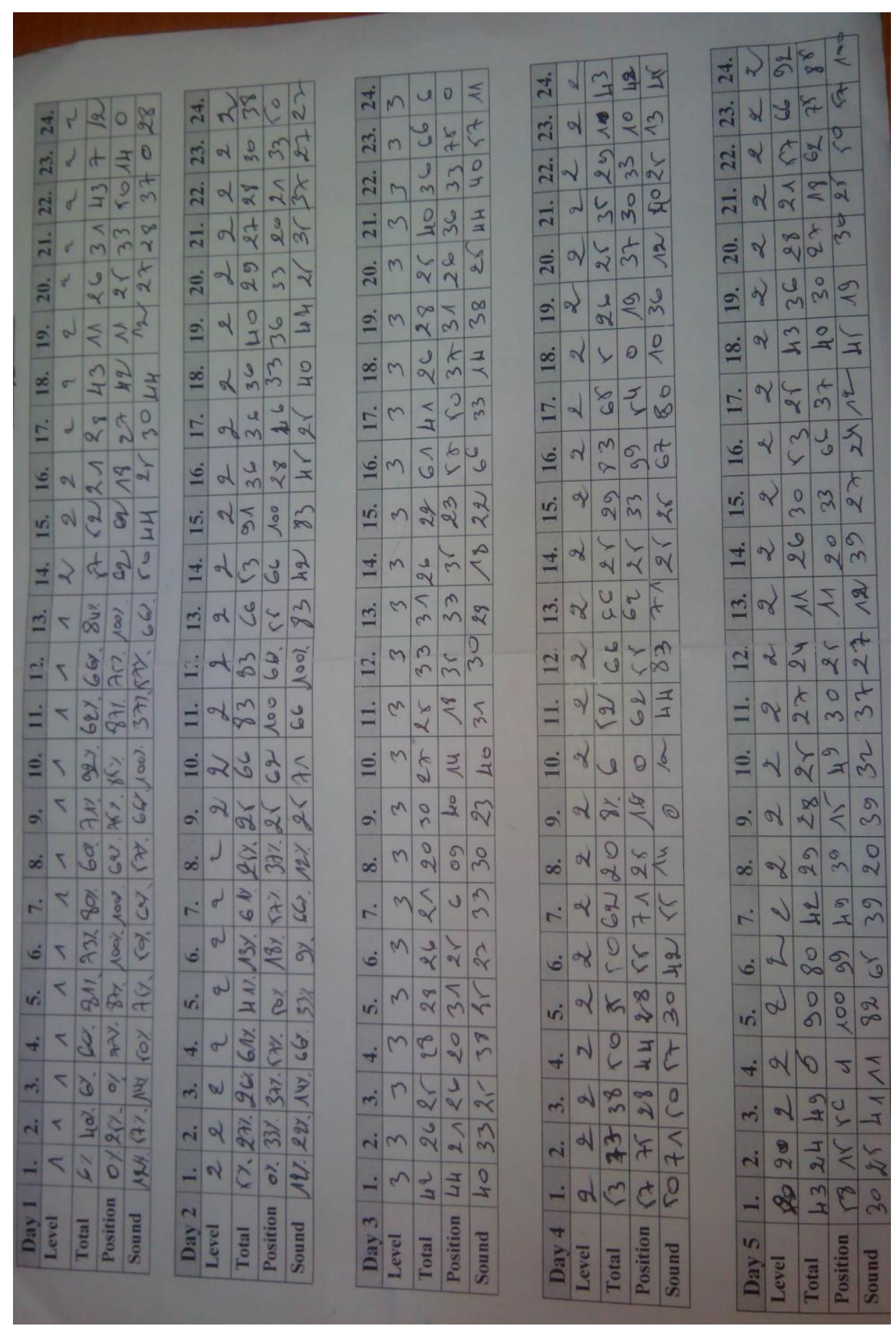

Appendix B- Second language writing anxiety inventory 
This survey was designed to help the researcher to better understand a bit about learners' writing habits. To effectively accomplish this, the researcher needs your help. Please respond to each statement by circling one of the numbers in the boxes. Your identity will be kept completely anonymous.

0 $=$ Never, $1=$ Rarely, $2=$ Sometimes, $3=$ Often, $4=$ Never

\begin{tabular}{|c|c|c|c|c|c|}
\hline 1. While writing in English, I get nervous. & $\mathbf{0}$ & 1 & 2 & 3 & 4 \\
\hline $\begin{array}{l}\text { 2. I feel my heart beating when writing English } \\
\text { composition (like paragraphs or essays) under a time } \\
\text { limit. }\end{array}$ & $\mathbf{0}$ & 1 & 2 & 3 & 4 \\
\hline $\begin{array}{l}\text { 3. Knowing that my writing will be evaluated makes } \\
\text { me worried or uneasy while writing. }\end{array}$ & $\mathbf{0}$ & 1 & 2 & 3 & 4 \\
\hline 4. I do my best to void writing English compositions. & $\mathbf{0}$ & 1 & 2 & 3 & 4 \\
\hline $\begin{array}{l}\text { 5. When I start to write English compositions, my mind } \\
\text { becomes empty. }\end{array}$ & $\mathbf{0}$ & 1 & 2 & 3 & 4 \\
\hline $\begin{array}{l}\text { 6. I worry that my English compositions are worse than } \\
\text { others }\end{array}$ & $\mathbf{0}$ & 1 & 2 & 3 & 4 \\
\hline $\begin{array}{l}\text { 7. I shake(when your whole body moves } \\
\text { uncontrollabaly usually because of fear) or sweat } \\
\text { when I write English compositions under time } \\
\text { pressure }\end{array}$ & $\mathbf{0}$ & 1 & 2 & 3 & 4 \\
\hline $\begin{array}{l}\text { 8. When my writing is to be evaluated, I worry about } \\
\text { getting a bad mark }\end{array}$ & $\mathbf{0}$ & 1 & 2 & 3 & 4 \\
\hline $\begin{array}{l}\text { 9. My thoughts get mixed up when I start writing under } \\
\text { a time limit. }\end{array}$ & O & 1 & 2 & 3 & 4 \\
\hline $\begin{array}{l}\text { 10. I would rather write in a different language than in } \\
\text { English. }\end{array}$ & $\mathbf{0}$ & 1 & 2 & 3 & 4 \\
\hline $\begin{array}{l}\text { 11. I am afraid of what other students would think of my } \\
\text { English composition. }\end{array}$ & $\mathbf{0}$ & 1 & 2 & 3 & 4 \\
\hline $\begin{array}{l}\text { 12. I become afraid that I would get asked to read what I } \\
\text { have written. }\end{array}$ & $\mathbf{0}$ & 1 & 2 & 3 & 4 \\
\hline $\begin{array}{l}\text { 13. I freeze up when I am unexpectedly asked to write an } \\
\text { English composition. }\end{array}$ & 0 & 1 & 2 & 3 & 4 \\
\hline $\begin{array}{l}\text { 14. I worry about what others think about my English } \\
\text { writing. }\end{array}$ & $\mathbf{0}$ & 1 & 2 & 3 & 4 \\
\hline $\begin{array}{l}\text { 15. I become worried that I would get selected to read } \\
\text { my writing in class }\end{array}$ & O & 1 & 2 & 3 & 4 \\
\hline
\end{tabular}




\section{Referrals and References:}

[1] - Olive, T. (2012). Writing and working memory: a summary of theories and findings In E.L. Grigorenko, E. Mambrino \& D.D. Preiss, Writing: A mosaic of new perspectives (pp. 125-140). Psychology Press.

[2] - Kellogg, R. T. (2008). Training writing skills: A cognitive development perspective. Journal of Writing Research, 1, 1-26.

[3] - Mohamed, M., \& Zouaoui, M. (2014). EFL writing hindrances and challenges: The case of second year students of English at Djillali Liabes. Journal of Educational and Social Research, 4(3), 149.

[4] - Baddeley, A. D. (2002). Is working memory still working?. European psychologist, 7(2), 85 .

[5] - Baddeley, A. D., \& Hitch, G. (1974). Working memory. In Psychology of learning and motivation (Vol. 8, pp. 47-89). Academic press.

[6] - Baddeley, A. D. (2000). The episodic buffer: a new component of working memory?. Trends in cognitive sciences, 4(11), 417-423.

[7] - Baddeley, A. D. (2012). Working memory: theories, models, and controversies. Annual review of psychology, 63, 1-29.

[8] - Baddeley, A.D., Gathercole, S.E. \& Papagno, C. (1998). The phonological loop as a language learning device. Psychological Review 105 (1), 158-173.

[9] - Linck, J. A., Osthus, P., Koeth, J. T., \& Bunting, M. F. (2014). Working memory and second language comprehension and production: A meta-analysis. Psychonomic bulletin \& review, 21(4), 861-883.

[10] - Skehan, P. (2002). Theorising and updating aptitude. Individual differences and instructed language learning, 2, 69-94.

[11] - Kirchner, W. K. (1958). "Age differences in short-term retention of rapidly changing information". Journal of Experimental Psychology. 55 (4): 352-358.

[12] - Jaeggi, S. M., Seewer, R., Nirkko, A. C., Eckstein, D., Schroth, G., Groner, R., et al., (2003). Does excessive memory load attenuate activation in the prefrontal cortex? Load-dependent processing in single and dual tasks: functional magnetic resonance imaging study, Neuroimage 19(2) 210-225.

[13] - Jaeggi, S. M., Buschkuehl, M., Jonides, J., \& Perrig, W. J. (2008). Improving fluid intelligence with training on working memory. Proceedings of the National Academy of Sciences, 105(19), 6829-6833.

[14] - Soveri, A., Antfolk, J., Karlsson, L., Salo, B., \& Laine, M. (2017). Working memory training revisited: A multi-level meta-analysis of n-back training studies. Psychonomic Bulletin \& Review, 24(4), 1077-1096.

[15] - McCutchen, D., Covill, A., Hoyne, S. H., \& Mildes, K. (1994). Individual differences in writing: Implications of translating fluency. Journal of Educational Psychology, 86(2), 256.

[16] - Hoskyn, M., \& Swanson, H. L. (2003). The relationship between WM and writing in younger and older adults. Reading \& Writing, 16(8), 759-784.

[17] - Vanderberg, R., \& Swanson, H. L. (2007). Which components of working memory are important in the writing process?. Reading and Writing, 20(7), 721-752.

[18] - Kellogg, R. T. (1996). A model of working memory in writing. In C. M. Levy \& S. E. Ransdell (Eds), The science of writing (pp. 57-71). Mahwah, NJ: Lawrence Erlbaum Associates. 
[19] - Bourdin, B., \& Fayol, M. (1994). Is written language production more difficult than oral language production? A working memory approach. International journal of psychology, 29(5), 591-620.

[20] - Lu, Y. (2015). 10 Working Memory, Cognitive Resources and L2 Writing Performance. Working Memory in Second Language Acquisition and Processing, 87, 175 .

[21] - Eysenck, M. W., \& Calvo, M. G. (1992). Anxiety and performance: The processing efficiency theory. Cognition \& Emotion, 6(6), 409-434.

[22] - Mitte, K. (2008). Memory bias for threatening information in anxiety and anxiety disorders: A meta-analytic review. Psychological Bulletin, 134(6), 886.

[23] - Moran, T. P. (2016). Anxiety and working memory capacity: A meta-analysis and narrative review. Psychological Bulletin, 142(8), 831.

[24] - Al Asmari, A. (2013). Investigation of Writing Strategies, Writing Apprehension, and Writing Achievement among Saudi EFL-Major Students. International Education Studies, 6(11), 130-143.

[25] - Lee, S. \& Krashen, S. (2002). Predictors of success in writing English as a foreign language: Reading, revision behavior, apprehension, and writing. College Student Journal, 36, 532-543.

[26] - Rezaei, M. M., Jafari, S. M., \& Younas, M. (2014). Iranian EFL students' writing anxiety: levels, causes and implications. English for Specific Purposes World, 42(15), 1-10.

[27] - Cheng, Y. (2004). A measure of second language writing anxiety: Scale development and preliminary validation. Journal of Second Language Writing, 13(4), 313-335. 